\title{
Characterization and verification of ACAM slit functions for trace-gas retrievals during the 2011 DISCOVER-AQ flight campaign
}

\author{
C. Liu ${ }^{1}$, X. Liu ${ }^{1}$, M. G. Kowalewski²,3 , S. J. Janz ${ }^{3}$, G. González Abad ${ }^{1}$, K. E. Pickering ${ }^{3}$, K. Chance ${ }^{1}$, and \\ L. N. Lamsal ${ }^{2,3}$ \\ ${ }^{1}$ Harvard-Smithsonian Center for Astrophysics, Cambridge, Massachusetts, USA \\ ${ }^{2}$ Goddard Earth Sciences Technology and Research, USRA, Greenbelt, Maryland, USA \\ ${ }^{3}$ NASA Goddard Space and Flight Center, Greenbelt, Maryland, USA
}

Correspondence to: X. Liu (xliu@cfa.harvard.edu)

Received: 6 October 2014 - Published in Atmos. Meas. Tech. Discuss.: 19 November 2014

Revised: 15 January 2015 - Accepted: 21 January 2015 - Published: 13 February 2015

\begin{abstract}
The Airborne Compact Atmospheric Mapper (ACAM), an ultraviolet/visible/near-infrared spectrometer, has been flown on board the NASA UC-12 aircraft during the Deriving Information on Surface Conditions from Column and Vertically Resolved Observations Relevant to Air Quality (DISCOVER-AQ) campaigns to provide remote sensing observations of tropospheric and boundary-layer pollutants from its radiance measurements. To assure the tracegas retrieval from ACAM measurements we perform detailed characterization and verification of ACAM slit functions. The wavelengths and slit functions of ACAM measurements are characterized for the air-quality channel $(\sim 304-500 \mathrm{~nm})$ through cross-correlation with a high-resolution solar irradiance reference spectrum after necessarily accounting for atmospheric gas absorption and the ring effect in the calibration process. The derived slit functions, assuming a hybrid combination of asymmetric Gaussian and top-hat slit functions, agree very well with the laboratory-measured slit functions. Comparisons of trace-gas retrievals between using derived and measured slit functions demonstrate that the crosscorrelation technique can be reliably used to characterize slit functions for trace-gas retrievals.
\end{abstract}

\section{Introduction}

Distinguishing near-surface pollution from satellite observations of total column abundances is one of the most challenging problems in Earth observations from space. The NASA Earth Venture Deriving Information on Surface Conditions from Column and Vertically Resolved Observations Relevant to Air Quality (DISCOVER-AQ) project was funded to tackle this challenge, relating column observations to surface concentrations for aerosols and key trace gases such as ozone $\left(\mathrm{O}_{3}\right)$, nitrogen dioxide $\left(\mathrm{NO}_{2}\right)$, and formaldehyde $\left(\mathrm{CH}_{2} \mathrm{O}\right)$ so as to improve the interpretation of satellite observations to diagnose near-surface conditions relating to air quality. The Airborne Compact Atmospheric Mapper (ACAM) is an ultraviolet (UV)/visible/near-infrared spectrometer covering the spectral range 304-910 nm (Kowalewski and Janz, 2009). It has been flown on board the NASA UC-12 aircraft in both nadir-viewing mode and much less frequently in zenith-sky mode during the DISCOVER-AQ campaigns as the primary airborne instrument to provide remote sensing column abundances of $\mathrm{O}_{3}, \mathrm{NO}_{2}$, and $\mathrm{CH}_{2} \mathrm{O}$ and explore $\mathrm{O}_{3}$ profile observations (Liu et al., 2005a).

To accurately retrieve trace gases from ACAM measurements it is important to perform accurate wavelength calibration and characterize the slit function. For satellite observations, wavelength and slit-function calibrations are typically performed through cross-correlation of the measured solar irradiance at the top of the atmosphere (TOA) (for both slit-function and wavelength calibration) and the measured Earth-shine radiance (for wavelength calibration only) with a high-resolution solar irradiance reference spectrum (Caspar and Chance, 1997; Chance, 1998; Chance and Kurucz, 2010), especially when accurate laboratory measurements of slit functions are not available. This cross-correlation technique has been applied to airborne or ground-based measurements (e.g., Roscoe et al., 2010; Merlaud et al., 2012; Popp et 
al., 2012) and is applied to ACAM measurements to characterize the slit functions and wavelength registration as a function of wavelength. Unlike satellite instruments, airborne or ground-based instruments do not measure the extraterrestrial TOA solar irradiance but radiances or direct irradiances that go through atmospheric absorption and/or Rayleigh scattering. Therefore, it might be important to include trace-gas absorption and filling in of the solar Fraunhofer lines through Raman scattering (called the ring effect in atmospheric spectroscopy) in the cross-correlation procedure, especially when atmospheric absorption is significant (e.g., in the $\mathrm{O}_{3}$ Hartley and Huggins bands). The inclusion of ring effect and tracegas absorption spectra for wavelength calibration was used in performing radiance wavelength calibration for the Ozone Monitoring Instrument (OMI) (Voors et al., 2006); however, how the derived slit functions or wavelength shifts are affected by the exclusion of ring effect and trace-gas absorption has not been presented in literature. Recently, ACAM slit functions have been measured using tunable narrow band lasers in the laboratory of the National Institute of Standards and Technology (NIST), and results became available for comparison after we developed the cross-correlation procedure for ACAM data. These measured slit functions are very valuable not only for improving trace-gas retrievals but also for verifying the results from the cross-correlation technique. If the cross-correlation technique (Caspar and Chance, 1997) is demonstrated to work well, this method can be reliably applied to many ground-based or airborne measurements when accurate measurements of slit functions as a function of wavelength are not available. Furthermore, the cross-correlation technique can complement the measured slit functions to monitor the in-flight variation of these parameters caused by thermal-induced variation and instrument degradation.

The main purposes of this paper are to perform ACAM wavelength and slit-function calibrations, compare derived and laboratory-measured slit functions for improving tracegas retrievals from ACAM measurements during the 2011 Baltimore-Washington, DC, DISCOVER-AQ campaign. It is organized as follows: the ACAM instrument, its characterization of slit functions and pre-mission spectral calibration, and data analysis are described in Sect. 2. Section 3 focuses on the wavelength and slit-function calibration, their comparison with laboratory-measured slit functions, and evaluation of different slit functions on trace-gas retrievals. Section 4 summarizes this study.

\section{ACAM instrument and data analysis}

\subsection{ACAM instrument}

The ACAM flown on board the NASA UC-12 aircraft was designed and built at the NASA Goddard Space Flight Center. Its science objective is to provide remote sensing obser- vations of tropospheric and boundary-layer pollutants (e.g., $\mathrm{O}_{3}, \mathrm{NO}_{2}, \mathrm{CH}_{2} \mathrm{O}$, aerosols), coastal ocean color and water vapor, and visible imagery for cloud and surface information. These observations help to serve as a basis to support the planning of future air-quality and ocean-science missions such as the Geostationary Coastal and Air Pollution Events (GEO-CAPE) mission (Fishman et al., 2012) recommended by the National Research Council's Earth Science Decadal Survey (NRC, 2007) and the first Earth Venture Instrument project Tropospheric Emissions: Monitoring of Pollution (TEMPO) (Chance et al., 2013), which is a pathfinder for GEO-CAPE. The engineering objectives of ACAM are to determine the detection limits of commercially available miniature spectrometers and to improve in-field absolute calibration of UV/visible measurements to the sub-5\% accuracy level (Kowalewski and Janz, 2009).

ACAM includes two Ocean Optics Czerny-Turner miniature spectrometers, the air-quality (AQ) spectrometer and the ocean-color $(\mathrm{OC})$ spectrometer, and a high-definition video camera $(2592 \times 1936$ pixels). The AQ spectrometer covers the spectral region $304-520 \mathrm{~nm}$ with a spectral resolution of $\sim 0.8 \mathrm{~nm}$ full width at half maximum (FWHM) and a spectral sampling of $\sim 0.1 \mathrm{~nm}$, optimized for the measurement of tropospheric pollutants. The OC spectrometer covers the spectral region $460-910 \mathrm{~nm}$ with a spectral resolution of $\sim 1.5 \mathrm{~nm}$ FWHM and spectral sampling of $\sim 0.19 \mathrm{~nm}$, optimized for ocean color and aerosols. ACAM can operate in two viewing modes: nadir mode, through a nadir port, and zenith-sky mode, through a zenith fiber port. No telescope is used on ACAM; a scan mirror is used instead to reflect the incoming light into the spectrometers' optical fibers. In nadir mode, ACAM scans across the track up to angles of $\pm 22.5^{\circ}$ with an angular sample dimension of $3.6 \times 5.6^{\circ}$ during a single integration period. Prior to the 2011 DISCOVER-AQ flight campaign, the ACAM instrument participated in four flight campaigns with $\sim 150$ flight hours of successful operations.

During the 2011 Baltimore-Washington, DC, DISCOVER-AQ campaign (1-29 July 2011), ACAM was flown on the UC-12 platform for 13.5 flight days, remaining fully operational without any anomalies or downtime. Each flight day has a morning and an afternoon flight of $\sim 4 \mathrm{~h}$ each. ACAM measurements covered various very clean to polluted conditions. Weather conditions were primarily cloud free except for several days with $30-40 \%$ cloud cover. The UC-12 aircraft typically flies at an altitude of $8.5 \mathrm{~km}$ with average ground speed of $110 \mathrm{~m} \mathrm{~s}^{-1}$. ACAM mainly operates in nadir mode and takes a zenith-sky measurement every 20-30 min. In nadir mode, it scans across the track in 10 steps, with a native spatial sampling of $\sim 0.75 \mathrm{~km}$ across the track by $\sim 0.5 \mathrm{~km}$ along the track at the $8.5 \mathrm{~km}$ flight altitude. The along-track sample distance during one complete scan is typically $1.1 \mathrm{~km}$. In this study, we use the step-pair average data, which give a spatial sampling cadence of $\sim 1.5 \times 0.5 \mathrm{~km}$. 
ACAM slit functions were measured at NIST using a solid-state tunable laser source over the spectrometer's full spectral range in $5 \mathrm{~nm}$ steps at $0.1 \mathrm{~nm}$ accuracy. The laser produced pulses at a repetition rate of $1 \mathrm{kHz}$ and $0.1 \mathrm{~nm}$ line width. These pulses entered a $6^{\prime \prime}$ internal diameter polytetrafluoroethylene integrating sphere mounted at the instrument's nadir view angle. The instrument was operated at flight temperatures and manually adjusted integration times in order to maximize sensitivity to the wings of the slit function.

Pre-mission spectral calibration was performed by diffusely illuminating the instrument field of view with multiple spectral line sources. Measurements of discrete spectral lines from mercury-argon and cadmium high-pressure discharge lamps were fit using skewed Gaussian line profiles. The area-weighted centroid of the line profiles was then fit to a third-order polynomial as a function of detector pixel in order to characterize the spectrometer's dispersion. The uncertainty in the laboratory spectral registration is approximately $0.03 \mathrm{~nm}$ FWHM, based on the standard deviation of the dispersion fit residuals. Small wavelength shifts can occur between shipment and flights as have been seen in previous ACAM missions, for example the Costa Rica Aura Validation Experiment in 2006 (CRAVE 2006). The one time wavelength shift can be caused by a number of things, like rough shipment to the hangar before integration or a small settling in the spectrometer optics. Post-mission spectral calibration can be similarly conducted to check the pre-mission spectral calibration.

\subsection{Data analysis algorithm}

The GOME/OMI $\mathrm{O}_{3}$ profile retrieval algorithm (Liu et al., 2005b, 2010) is adapted to analyze ACAM data, performing wavelength and slit-function calibrations and fitting trace-gas absorption to retrieve trace-gas columns. The $\mathrm{O}_{3}$ profile algorithm is based on the Smithsonian Astrophysical Observatory basic optical absorption spectroscopy (BOAS) tracegas fitting algorithm, using a nonlinear least-squares inversion technique (Chance, 1998), and adds the $\mathrm{O}_{3}$ profile retrieval capability to perform radiative calculations and retrieve $\mathrm{O}_{3}$ profile using the optimal estimation inversion technique. Both trace-gas fitting and $\mathrm{O}_{3}$ profile algorithms minimize the differences between simulated and observed radiance spectra. We use the BOAS algorithm for the ACAM data analysis, in which simulation is iteratively done using an empirical model described below.

In the BOAS algorithm, simulation of radiance $I_{\mathrm{S}}(\lambda)$ in both wavelength/slit-function calibration and trace-gas fitting can be generically described by the following equation:

$$
\begin{aligned}
& I_{\mathrm{s}}(\lambda)=\left[\left(A I_{0}(\lambda+\Delta \lambda)+\sum_{i} a_{1, i} X_{1, i}(\lambda)\right)\right. \\
& \left.\times \exp \left(-\sum_{i} n_{i} \sigma_{i}(\lambda)\right)+\sum_{i} a_{2, i} X_{2, i}(\lambda)\right] P_{\mathrm{s}}^{m}(\lambda)+P_{\mathrm{b}}^{m}(\lambda),
\end{aligned}
$$

where $I_{0}(\lambda)$ is the reference spectrum, $A$ is the scaling parameter for $I_{0}$, and $I_{0}(\lambda+\Delta \lambda)$ indicates the process of wavelength calibration/registration (e.g., shift and squeeze, used in this study, or polynomial). $X_{1, i}(\lambda), \sigma_{i}(\lambda)$, and $X_{2, i}(\lambda)$ are the basis functions in initial add-on, Beer's law, and second add-on modes, respectively, and $a_{1, i}, n_{i}$, and $a_{2, i}$ are the corresponding coefficients. The basis functions can include trace-gas cross sections, ring effect, undersampling spectra, and common residual spectra. Each basis function is typically included in only one of the modes (e.g., cross sections as $\sigma_{i}$, ring effect (Chance and Spurr, 1997) as $X_{1, i}$, and common mode as $\left.X_{2, i}\right) . I_{0}$ is either the reference spectrum (e.g., for trace-gas fitting) or can be derived from a high-resolution solar irradiance reference spectrum $I_{\mathrm{h} 0, \lambda^{\prime}}$, convolved with slit functions $S_{\lambda}$ when doing wavelength and slit-function calibrations as

$I_{0}(\lambda)=\int_{\lambda^{\prime}} I_{\mathrm{h} 0, \lambda^{\prime}} S_{\lambda^{\prime}} \mathrm{d} \lambda^{\prime} / \int_{\lambda^{\prime}} S_{\lambda^{\prime}} \mathrm{d} \lambda^{\prime}$.

In this study, we use the recently published high-resolution solar reference spectrum by Chance and Kurucz (2010), which is radiometrically calibrated to an absolute solar reference spectrum from ATLAS shuttle flights measured at coarser spectral resolution (Thuillier et al., 2004). $\sigma(\lambda)$ are the effective cross sections at instrument resolution. They can be derived by convolving high-resolution cross sections $\sigma_{\mathrm{h}, \lambda}$ (neglecting the slit functions of the laboratory cross-section measurements due to their much higher resolutions) with instrument slit functions in a way correcting for the solar- $I_{0}$ effect (Aliwell et al., 2002):

$$
\begin{aligned}
& \delta(\lambda)=-\frac{1}{m} \ln \left[\int_{\lambda^{\prime}} \exp \left(-m \delta_{\mathrm{h}, \lambda^{\prime}}\right) I_{\mathrm{h} 0, \lambda^{\prime}} S_{\lambda^{\prime}} d \lambda^{\prime} /\right. \\
& \left.\int_{\lambda^{\prime}} I_{\mathrm{h} 0, \lambda^{\prime}} S_{\lambda^{\prime}} d \lambda^{\prime}\right],
\end{aligned}
$$

where $m$ is selected as the typical column amount corresponding to each trace gas because its value only slightly affects the correction of the solar- $I_{0}$ effect (Aliwell et al., 2002). $P_{\mathrm{s}}^{m}(\lambda)$ and $P_{\mathrm{b}}^{m}(\lambda)$ are the scaling and baseline $m$ thorder polynomials, respectively, defined as

$$
P^{m}(\lambda)=\sum_{i=0}^{m} P_{i}\left(\lambda-\lambda_{\mathrm{avg}}\right)^{i},
$$


where $P_{i}$ is the coefficient for each order and $\lambda_{\text {avg }}$ is the average wavelength of the fitting window. For previous GOME, OMI, and GOME-2 satellite instruments, we have typically assumed slit functions $S_{\lambda}$ to be Gaussian or asymmetric Gaussian (Chance, 1998; Liu et al., 2005b, 2010; Cai et al., 2012). Initial comparison of derived with measured slit functions at some wavelengths suggests that the measured slit width is slightly broader near the top and slightly narrower near the bottom, so we implement a broadened Gaussian shape slit function, i.e., a hybrid combination of asymmetric Gaussian $S_{\mathrm{g}, \lambda}$ and top-hat $S_{\mathrm{t}, \lambda}$ slit functions weighted by $1-f_{\mathrm{t}}$ and $f_{\mathrm{t}}$ ( $f_{\mathrm{t}}$ ranges from 0 to 1$)$, respectively, defined as follows:

$$
\begin{aligned}
S_{\lambda} & =S_{\mathrm{g}, \lambda}\left(1-f_{\mathrm{t}}\right)+S_{\mathrm{t}, \lambda} f_{\mathrm{t}} \\
& =\exp \left\{-\left[\frac{\Delta \lambda}{h_{\mathrm{g}}\left(1+\operatorname{sgn}(\Delta \lambda) a_{\mathrm{g}}\right)}\right]^{2}\right\}\left(1-f_{\mathrm{t}}\right) \\
& +\exp \left\{-\left[\frac{\Delta \lambda}{h_{\mathrm{t}}\left(1+\operatorname{sgn}(\Delta \lambda) a_{\mathrm{t}}\right)}\right]^{4}\right\} f_{\mathrm{t}},
\end{aligned}
$$

where $h_{\mathrm{g}} / a_{\mathrm{g}}$ and $h_{\mathrm{t}} / a_{\mathrm{t}}$ are the half-width at $1 / e$ intensity/asymmetric factor for each slit function, respectively, $\Delta \lambda$ is the wavelength difference from the wavelength to be weighted to the slit center, and sgn is the sign function. Equation (5) can be used to represent pure/asymmetric Gaussian/top-hat slit functions if some variables are fixed. For example, if $f_{\mathrm{t}}$ is fixed to be $0 / 1$, the slit function becomes asymmetric Gaussian/top-hat; if $f_{\mathrm{t}}$ is $0 / 1$ and $a_{\mathrm{g}} / a_{\mathrm{t}}$ is 0 , the slit function becomes pure Gaussian/top-hat. A similar hybrid slit function has been used to parameterize OMI laboratory-measured slit functions (Dirksen et al., 2006). The main differences are that we introduce the use of asymmetric factors to represent the slit asymmetry and we do not include offsets from slit center (i.e., slit always peaks at $\Delta \lambda=0$ ), as the offsets are highly correlated with wavelength shift parameters so that the fitting is difficult to converge.

The above equations describe the model to simulate radiances for doing wavelength and slit-function calibrations. If slit functions are known, either pre-determined from fitting or laboratory measurements, the above algorithm can be used to do wavelength calibration after convolution with the known slit functions. The trace-gas fitting is almost the same except that the irradiance reference spectrum and slitfunction parameters are pre-determined.

\section{Instrument wavelength and slit-function calibration}

\subsection{Impacts of including absorption and ring effect}

To investigate whether it is necessary to account for tracegas absorption and ring effect in the calibration process, we compare fitting residuals, fitted slit functions (broadened slit function), and wavelength shifts with and without accounting
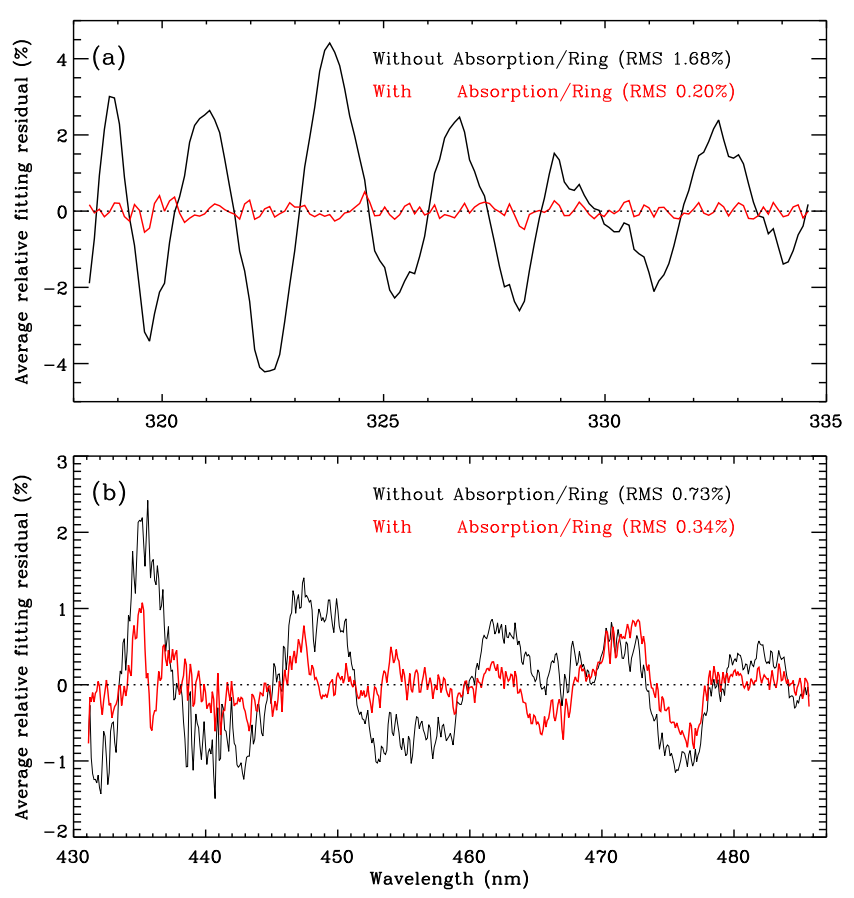

Figure 1. Comparison of average relative fitting residuals for ACAM data from 21 July 2011, with and without considering absorption and ring effect for (a) the $\mathrm{O}_{3}$ fitting window and (b) the $\mathrm{NO}_{2}$ fitting window. The values in parentheses indicate the average root mean square (RMS) of the relative fitting residuals.

for the absorption and ring effect. Figure 1 presents the average relative fitting residuals of wavelength and slit-function calibration for the two cases in the $\mathrm{O}_{3}$ and $\mathrm{NO}_{2}$ fitting windows. As expected, the inclusion of these effects significantly reduces fitting residuals, especially in the $\mathrm{O}_{3}$ fitting window, due to very strong ozone absorption. The relative fitting root mean squares $(\mathrm{RMS})$ of the residuals are reduced from $\sim 1.7$ to below $0.2 \%$ in the $\mathrm{O}_{3}$ fitting window and from 0.73 to $0.34 \%$ in the $\mathrm{NO}_{2}$ fitting window. Note that the large residuals even with absorption and ring effect are due to systematic radiometric differences between ACAM measurements and the high-resolution reference.

To compare the derived slit functions and wavelength shifts throughout the ACAM AQ channel, we perform calibrations in windows of 201 spectral pixels $(\sim 20 \mathrm{~nm})$ with 3 -pixel increments sliding through the channel for a selected ACAM ground pixel. All slit parameters and wavelength shifts (derived from shift and squeeze parameters) from initial wavelength assignment in ACAM data for all windows including a particular wavelength are averaged to derive the parameters for that wavelength. Due to the use of five parameters in the slit function, we only compare the slit FWHMs derived from the slit parameters. Figure 2 compares the derived slit FWHMs and wavelength shifts in the ACAM AQ channel $(\sim 304-500 \mathrm{~nm})$ for the two cases. Without the absorption and ring effect, the slit FWHMs 

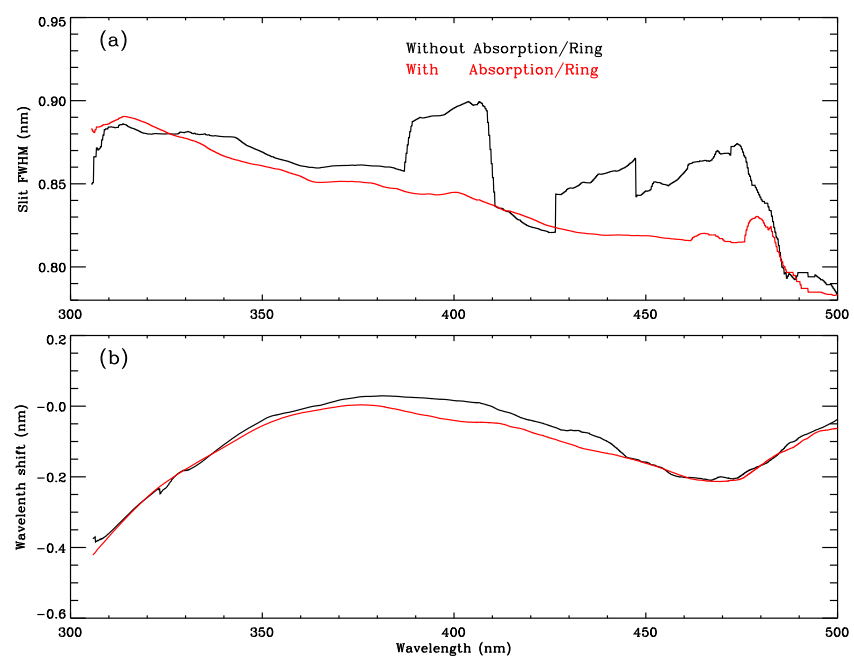

Figure 2. Comparison of derived (a) slit full width at half maximum (FWHM) and (b) wavelength shift as functions of wavelength for the ACAM air-quality channel $(304-500 \mathrm{~nm})$, with and without accounting for the absorption and ring effect, for a pixel from 21 July 2011. The slit functions and wavelength shifts are derived over a range of 201 ACAM pixels $(\sim 20 \mathrm{~nm})$ in 3-pixel increments sliding through the channel. The derived slit and wavelength parameters at a wavelength are the average of the corresponding parameters in all windows including this wavelength.

show more wavelength-dependent variation and are typically overestimated by $0.01-0.06 \mathrm{~nm}$. The large overestimation of $\sim 0.05$ at $\sim 400 \mathrm{~nm}$ is due to neglecting the filling in of calcium II $\mathrm{H}$ and $\mathrm{K}$ Fraunhofer lines, and the overestimation of $\sim 0.02-0.05$ around $430-480 \mathrm{~nm}$ is mainly due to the neglect of ring effect, $\mathrm{O}_{2}-\mathrm{O}_{2}$, and $\mathrm{O}_{3}$ absorption. The derived slit functions are also less stable and vary more from ground pixel to pixel, especially in these two regions around 400 and $450 \mathrm{~nm}$. Finally, the wavelength shift is less sensitive to the inclusion of absorption and the ring effect but can differ by up to $\sim 0.08 \mathrm{~nm}$ especially around $370-440 \mathrm{~nm}$. The impacts of including absorption and ring effect on slit widths and wavelength shifts are very similar when assuming asymmetric Gaussian slit functions. These significant differences indicate that atmospheric gas absorption and the ring effect should be considered in the slit-function calibration of ACAM radiances. A potential problem of including absorption in the wavelength calibration is that wavelength errors in the laboratory cross sections especially for the major absorbers can propagate to affect the derived wavelength shifts.

\subsection{Derivation of ACAM wavelength registration and slit functions}

Figure 3 presents time series of derived slit FWHMs (assuming broadened Gaussian) for $\mathrm{O}_{3}(318-335 \mathrm{~nm})$ and $\mathrm{NO}_{2}$ (430-486 nm) fitting windows for all the ACAM ground pixels on 21 July 2011. There are variations of up to $0.08 \mathrm{~nm}$

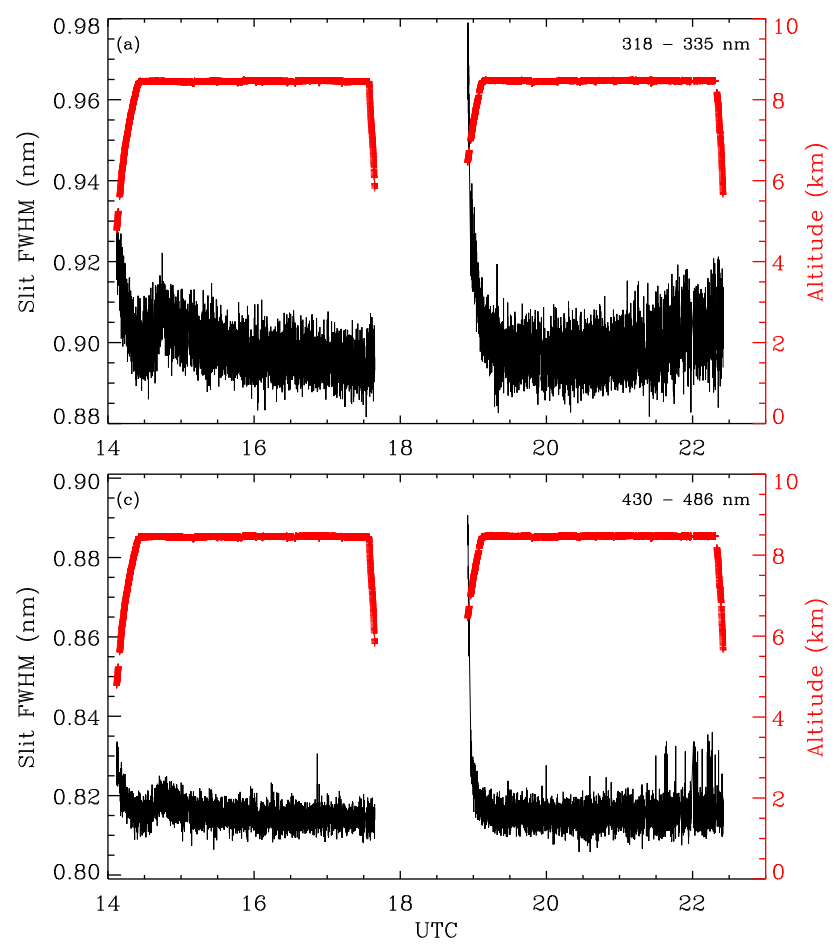

Figure 3. Time series of derived slit full width at half maximum (FWHM, black line) for the $\mathrm{O}_{3}(318-335 \mathrm{~nm})$ and $\mathrm{NO}_{2}(430$ $486 \mathrm{~nm}$ ) fitting windows from ACAM data from 21 July 2011. The red symbols indicate the corresponding flight altitude.

after the aircraft takeoff while the sensor and detector temperature take up to $45 \mathrm{~min}$ to stabilize. The slit parameters then become relatively more stable, with smaller fluctuations of $\sim 0.01-0.02 \mathrm{~nm}$ likely due to a combination of thermalinduced variations and uncertainties in the derived slit parameters. Those fluctuations indicate that we need to average results from more ACAM ground pixels to derive accurate ACAM slit functions for temperature-stabilized operating conditions. For retrievals from pixels during the takeoff it might be important to account for the temporal variation of the slit functions.

To average the derived slit and wavelength parameters, we perform calibrations for 53 ACAM ground pixels from 21 July 2011 after the UC-12 aircraft is cruising at a nearly constant flight altitude (i.e., after the ACAM sensor temperature becomes stable). Figure $4 \mathrm{a}-\mathrm{c}$ compares the average derived slit functions assuming asymmetric/broadened Gaussian slit functions with laboratory measurements at three wavelengths $\left(325,340\right.$, and $460 \mathrm{~nm}$, representing the $\mathrm{O}_{3}$, $\mathrm{CH}_{2} \mathrm{O}$, and $\mathrm{NO}_{2}$ fitting windows, respectively). The derived asymmetric Gaussian slit functions generally agree well with measured slit functions. However, the widths are generally narrower around the centers and wider near the wings. The derived broadened Gaussian slit functions clearly match the measurements better around both the centers and wings for all the wavelengths, although there are still some notable 

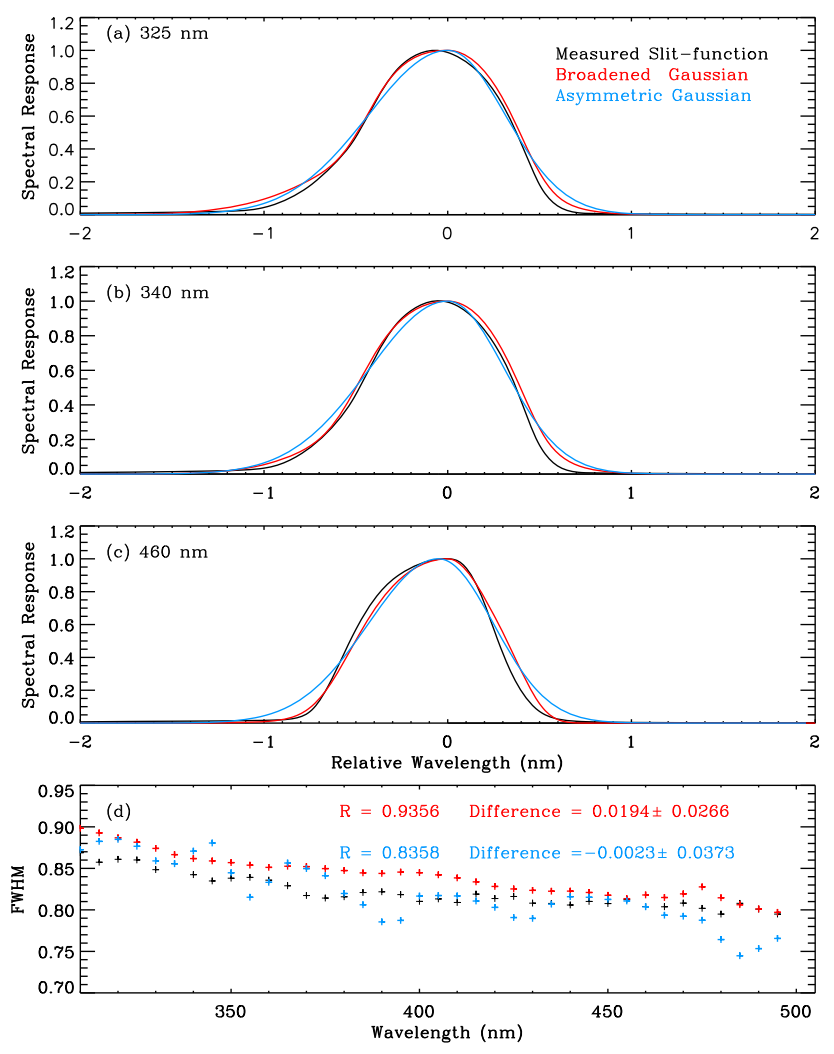

Figure 4. Comparison of derived ACAM asymmetric Gaussian (blue) and broadened Gaussian (red) slit functions with laboratorymeasured slit functions (black) at (a) 325, (b) 340, and (c) $460 \mathrm{~nm}$, representing the $\mathrm{O}_{3}, \mathrm{CH}_{2} \mathrm{O}$, and $\mathrm{NO}_{2}$ fitting windows, respectively. The measured slit function has been shifted -0.07 in (a) and $0.05 \mathrm{~nm}$ in (b), and the asymmetric Gaussian slit function has been shifted $-0.05 \mathrm{~nm}$ in (c). (d) Comparison of derived slit full width at half maximum (FWHM) as a function of wavelength. The correlations, mean differences, and $1 \sigma$ standard deviations with respect to the measured slit FWHMs are shown.

differences especially around the wings. Figure $4 d$ compares the derived and measured slit FWHMs. The derived broadened Gaussian slit FWHMs correlate with the measured slit FWHMs (with a linear correlation $R$ of 0.94 ) better than the asymmetric Gaussian slit FWHMs $(R=0.84)$ with smaller standard deviations of the differences, although their differences from the measured slit FWHMs are larger by $\sim 0.02 \mathrm{~nm}$ on average. The larger derived FWHMs assuming broadened Gaussian slit function are likely due to the shape differences between measured and derived slit functions, the lack of sensitivity to pull out the wing structures so that the algorithm weights the core more than the wings, and small changes in slit widths. Based on the comparison, the broadened Gaussian slit function is selected to represent the ACAM slit function.

Figure 5 shows the derived slit parameters (assuming broadened Gaussian slit function) as well as wavelength shifts as functions of wavelength for the 53 ground pixels.
All the ground pixels show significant yet similar spectral variations in the slit parameters. There are some slight variations from ground pixel to pixel as expected from Fig. 3 . The relatively larger variation in individual slit parameters around 400 and $480 \mathrm{~nm}$ is due to larger uncertainties in the competitive determination of slit parameters for asymmetric Gaussian and asymmetric top-hat functions although the combined overall slit functions show less variation. Due to the variation among pixels, we use the average wavelengthdependent slit parameters (black lines) to represent ACAM slit functions under stabilized operating conditions. The wavelength calibration shows large wavelength shifts of up to $-0.4 \mathrm{~nm}$ from the pre-mission wavelength registration. This shift has been verified in post-mission calibration and is likely due to one time wavelength shift between shipments and flights as mentioned in Sect. 2.1. To reduce highfrequency fine structures in the wavelength dependence of spectral intervals, we fit a sixth-order polynomial to the average wavelength shifts because it provides a better minimization than lower- or higher-order polynomials. We then add it to the initial wavelength grid to define the new wavelength grid. The derived slit FWHMs and wavelength shifts are similar and typically within $0.015 \mathrm{~nm}$ on different days, so we use these slit parameters and this new wavelength grid for all the ACAM data during the 2011 DISCOVER-AQ campaign except for data during the aircraft takeoff and landing, which are skipped in current processing.

Despite the use of $\sim 50$ ground pixels in the calibration, we found that the derived slit parameters from an average radiance spectrum are very similar to the average slit parameters from many pixels, suggesting that significant speed-up can be achieved in the slit-function and wavelength calibration process. In addition, the time-consuming process of performing calibration in 545-20 $\mathrm{nm}$ windows sliding through the channel in 3-pixel increments is to characterize the wavelength dependence of the slit functions. For spectral regions with less spectral variation in the slit functions, the calibration process can be quickly done using the retrieval fitting window on the ground pixel level (e.g., results in Fig. 3), accounting for the variation of slit functions from pixel to pixel.

\subsection{Evaluation of different slit functions on trace-gas retrievals}

To evaluate the quality of derived slit functions, we compare the $\mathrm{O}_{3}, \mathrm{CH}_{2} \mathrm{O}$, and $\mathrm{NO}_{2}$ retrievals using the derived asymmetric and broadened Gaussian slit functions with those using the measured slit functions. The fitting windows are optimized to 318-335, 324-357, and 430-486 nm, respectively. For all the slit functions, we use the average slit functions over the fitting windows. Average radiance spectra over selected ground pixels are used as reference spectra in the fittings so differential slant column densities (DSCDs) are derived. Figure 6 compares the fitted DSCDs and the DSCD differences between using derived and measured slit func- 

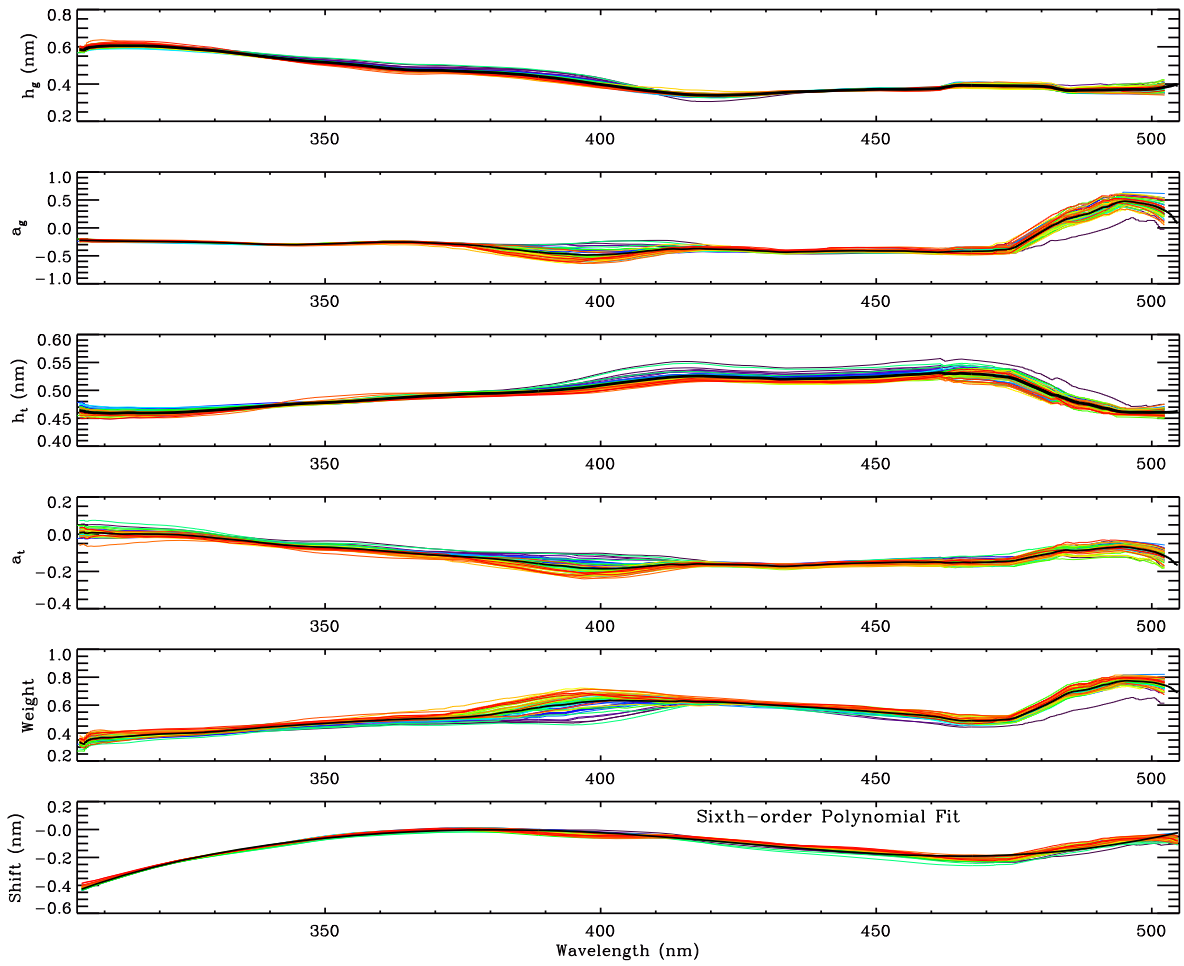

Figure 5. Derived asymmetric Gaussian slit half-width at $1 / e$ intensity $\left(h_{\mathrm{g}}\right)$, asymmetry factor $\left(a_{\mathrm{g}}\right)$, asymmetric top-hat slit half-width at $1 / e$ intensity $\left(h_{\mathrm{t}}\right)$ and asymmetric factor $\left(a_{\mathrm{t}}\right)$, the fraction of top-hat slit function, and wavelength shift from the initial wavelength assignment as functions of wavelength in the ACAM air-quality channel using 53 ACAM ground pixels on 21 July 2011. Different colors are for different ACAM pixels; the black lines are the average parameters (slit parameters) or a sixth-order polynomial fit (wavelength shift). The slit parameters and wavelength shifts are derived over a range of 201 ACAM pixels $(\sim 20 \mathrm{~nm})$ in 3-pixel increments sliding through the channel. The derived parameters at a wavelength are the average of these parameters in all windows including this wavelength.

tions. Due to the use of reference spectra measured by the same instrument, the fitting residuals are much smaller than those in Fig. 1: $\sim 0.12 \%$ for $\mathrm{O}_{3}$ and $\mathrm{CH}_{2} \mathrm{O}$ and $\sim 0.1 \%$ for $\mathrm{NO}_{2}$. Using the derived slit functions leads to comparable fitting precisions (based on fitting RMS and covariance matrix) and residuals with those using the measured slit functions except for clear improvement in $\mathrm{CH}_{2} \mathrm{O}$ fitting. The mean biases and standard deviations of the differences of using both derived slit functions are much smaller than the $\mathrm{CH}_{2} \mathrm{O}$ and $\mathrm{NO}_{2}$ fitting precisions. Using both derived slit functions produces similar $\mathrm{O}_{3}$ DSCDs relative to those using measured slit functions, with small mean biases and standard deviations of $\sim-1.2 \pm 1.1 \mathrm{DU}$. These values are about half of the mean fitting precision of $\sim 2.3 \mathrm{DU}$, although the retrieved DSCDs show systematic biases varying with solar zenith angle (time) from $\sim 1$ to $\sim-2.5 \mathrm{DU}$. The retrieval evaluations demonstrate that the cross correlation technique provides a reliable alternative to characterize ACAM slit functions for trace-gas retrievals.

Although using broadened Gaussian slit functions improves the slit-function characterization, as shown in Fig. 3, more than using the asymmetric Gaussian slit functions, the improvement on trace-gas retrievals is not significant, as the retrieval differences are small w.r.t. their fitting precisions. We also tried to fix $a_{\mathrm{g}}$ and $a_{\mathrm{t}}$ to 0 to derive slit functions. The derived slit widths compare less well with the measured slit widths than letting $a_{\mathrm{g}}$ and $a_{\mathrm{t}}$ vary, and the fitting precisions are slightly worse and the differences (w.r.t. using measured slit functions) are slightly larger than using asymmetric Gaussian for $\mathrm{O}_{3}$ and $\mathrm{CH}_{2} \mathrm{O}$ but better for $\mathrm{NO}_{2}$. Using even more complicated parameterization should be able to improve the agreement with laboratory slit functions, but the improvement on trace-gas retrievals of $\mathrm{O}_{3}, \mathrm{CH}_{2} \mathrm{O}$, and $\mathrm{NO}_{2}$ are likely not significant. From the point of view of characterizing the slit function over the entire channel, using all five parameters provides the best results. But for some specific spectral regions, it is possible that using fewer parameters might improve the slit functions. As for trace-gas retrievals, it is acceptable to use simpler slit functions (e.g., asymmetric Gaussian).

\section{Summary}

The Airborne Compact Atmospheric Mapper, an ultraviolet/visible/near-infrared spectrometer, was flown on board the NASA UC-12 aircraft during the DISCOVER- 

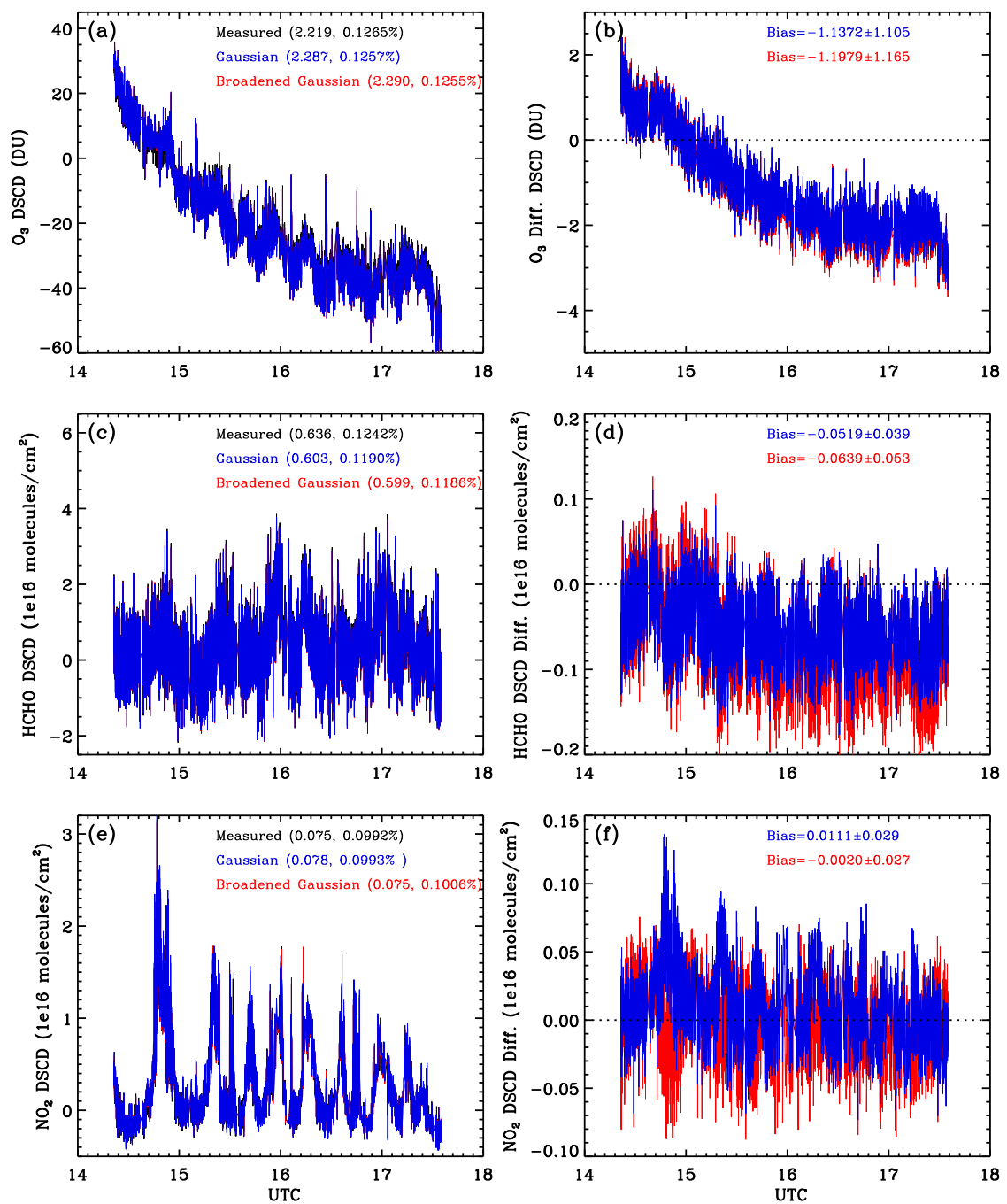

Figure 6. (Left) Comparison of fittings of $\mathrm{O}_{3}, \mathrm{CH}_{2} \mathrm{O}$, and $\mathrm{NO}_{2}$ : differential (relative to average nadir references) slant column densities (DSCDs) from 21 July 2011 using derived Gaussian (blue) and broadened Gaussian (red) and measured (black) slit functions; (right) the DSCD differences between derived and measured slit functions (derived-measured). The legends show average fitting precisions together with mean fitting residuals for left panels and mean biases and their standard deviations for right panels.

AQ campaigns as the main airborne instrument to provide remote sensing column observations of several key trace gases including $\mathrm{O}_{3}, \mathrm{NO}_{2}$, and $\mathrm{CH}_{2} \mathrm{O}$. To improve the trace-gas retrievals from ACAM radiance spectra, we perform detailed wavelength and slit-function calibrations for the air-quality channel $(\sim 304-500 \mathrm{~nm})$ through crosscorrelation of ACAM nadir radiances to a high-resolution solar irradiance reference spectrum by assuming asymmetric Gaussian and broadened Gaussian (i.e., a hybrid combination of asymmetric Gaussian and top-hat) slit functions. As ACAM measurements always contain signatures from atmospheric trace-gas absorption and the ring effect, we found out that it is necessary to take them into account in the cross-correlation calibration process. Without accounting for these effects, the derived slit functions show more spectral variation and the slit widths in full width at half maximum are overestimated by $\sim 0.01-0.06 \mathrm{~nm}$. The derived slit functions show significant temporal variation after the aircraft takeoff before the sensor and detector temperatures are stabilized and show some fluctuations afterwards, probably due to uncertainties in the slit-function calibration and thermally induced variations; thus we derive average slit functions and wavelength shifts using $\sim 53$ pixels after the ACAM instrument becomes more stable. The derived slit functions assuming broadened Gaussian slit functions agree very well with laboratory measured slit functions, better than the assumed asymmetric Gaussian slit functions both near the centers and the wings. The initial wavelength registration shows wavelength shifts of up to $\sim-0.4 \mathrm{~nm}$, which are corrected by fitting a sixth-order polynomial to 
the wavelength shifts. Trace-gas retrievals of $\mathrm{O}_{3}, \mathrm{CH}_{2} \mathrm{O}$, and $\mathrm{NO}_{2}$ using derived slit functions agree very well with those using measured slit functions to fitting precisions, demonstrating that the cross-correlation technique can be reliably used to characterize slit function for trace-gas retrievals.

Acknowledgements. Funding for this work at Smithsonian Astrophysical Observatory is provided by NASA Grants NNX11AH77G and NNX12AJ66G, as part of the NASA Earth Venture-1 DISCOVER-AQ project, and by the Smithsonian Institution. We acknowledge James Crawford for his strong support of this work.

Edited by: M. Van Roozendael

\section{References}

Aliwell, S. R., Van Roozendael, M., Johnston, P. V., Richter, A., Wagner, T., Arlander, D. W., Burrows, J. P., Fish, D. J., Jones, R. L., Tørnkvist, K. K., Lambert , J.-C., Pfeilsticker, K., and Pundt, I.: Analysis for $\mathrm{BrO}$ in zenith-sky spectra: An intercomparison exercise for analysis improvement, J. Geophys. Res., 107, 4199, doi:10.1029/2001JD000329, 2002.

Cai, Z., Liu, Y., Liu, X., Chance, K., Nowlan, C. R., Lang, R., Munro, R., and Suleiman, R.: Characterization and correction of Global Ozone Monitoring Experiment 2 ultraviolet measurements and application to ozone profile retrievals, J. Geophys. Res., 117, 07305, doi:10.1029/2011JD017096, 2012.

Caspar, C. and Chance, K.: GOME wavelength calibration using solar and atmospheric spectra, Third ERS Symposium on Space at the Service of our Environment, Florence, Italy, 14-21 March, 1997.

Chance, K.: Analysis of $\mathrm{BrO}$ measurements from the Global Ozone Monitoring Experiment, Geophys. Res. Lett., 25, 3335-3338, 1998.

Chance, K. and Kurucz, R. L.: An improved high-resolution solar reference spectrum for Earth's atmosphere measurements in the ultraviolet, visible, and near infrared, J. Quant. Spectrosc. Radiat. Transfer, 111, 1289-1295, 2010.

Chance, K. V. and Spurr, R. J. D.: Ring effect studies: Rayleigh scattering, including molecular parameters for rotational Raman scattering, and the Fraunhofer spectrum. Appl. Opt., 36, 52245230, 1997.

Chance, K., Liu, X., Suleiman, R., Flittner, D., Al-Saadi, J., and Janz, S.: Tropospheric emissions: Monitoring of pollution (TEMPO), Proc. SPIE, Vol. 8866, Earth Observing Systems XVIII, 88660D, doi:10.1117/12.2024479, 2013.

Dirksen, R., Dobber, M., Voors, R., and Levelt, P.: Prelaunch characterization of the Ozone Monitoring Instrument transfer function in the spectral domain, Appl. Opt., 45, 3972-3981, doi:10.1364/ao.45.003972, 2006.

Fishman, J., Iraci, L. T., Al-Saadi, J., Chance, K., Chavez, F., Chin M., Coble, P., Davis, C., DiGiacomo. P. M., Edwards, D., Eldering, A., Goes, J., Herman, J., Hu, C., Jacob, D. J., Jordan, C., Kawa, S. R., Key, R., Liu, X., Lohrenz, S., Mannino, A., Natraj, V., Neil, D., Neu, J., Newchurch, M., Pickering, K., Salisbury, J., Sosik, H., Subramaniam, A., Tzortziou, M., Wang, J., and Wang
M.: The United States' Next Generation of Atmospheric Composition and Coastal Ecosystem Measurements: NASA's Geostationary Coastal and Air Pollution Events (GEO-CAPE) Mission, Bull. Amer. Meteor. Soc., 93, 1547-1566, 2012.

Kowalewski, M. G. and Janz, S. J.: Remote Sensing Capabilities of the Airborne Compact Atmospheric Mapper, in: Proceedings of SPIE, San Diego, California, USA, 2-6 August 2009, Earth Observing Systems XIV, 74520Q, doi:10.1117/12.827035, 2009.

Liu, X., Sioris, C. E., Chance, K., Kurosu, T. P., Newchurch, M. J., Martin, R. V., and Palmer, P. I.: Mapping tropospheric ozone profiles from an airborne UV/Visible spectrometer, Appl. Opt., 44, 3312-3319, 2005a.

Liu, X., Chance, K., Sioris, C. E., Spurr, R. J. D., Kurosu, T. P., Martin, R. V., and Newchurch, M. J.: Ozone profile and tropospheric ozone retrievals from Global Ozone Monitoring Experiment: Algorithm description and validation, J. Geophys. Res., 110, D20307, doi:10.1029/2005JD006240, 2005 b.

Liu, X., Bhartia, P. K., Chance, K., Spurr, R. J. D., and Kurosu, T. P.: Ozone profile retrievals from the Ozone Monitoring Instrument, Atmos. Chem. Phys., 10, 2521-2537, doi:10.5194/acp-10-25212010, 2010.

Merlaud, A., Van Roozendael, M., van Gent, J., Fayt, C., Maes, J., Toledo-Fuentes, X., Ronveaux, O., and De Mazière, M.: DOAS measurements of $\mathrm{NO}_{2}$ from an ultralight aircraft during the Earth Challenge expedition, Atmos. Meas. Tech., 5, 2057-2068, doi:10.5194/amt-5-2057-2012, 2012.

National Research Council (NRC): Earth science and applications from space: national imperatives for the next decade and beyond, the National Academy of Sciences, Washington, DC, 2007.

Popp, C., Brunner, D., Damm, A., Van Roozendael, M., Fayt, C., and Buchmann, B.: High-resolution $\mathrm{NO}_{2}$ remote sensing from the Airborne Prism EXperiment (APEX) imaging spectrometer, Atmos. Meas. Tech., 5, 2211-2225, doi:10.5194/amt-5-22112012, 2012.

Roscoe, H. K., Van Roozendael, M., Fayt, C., du Piesanie, A., Abuhassan, N., Adams, C., Akrami, M., Cede, A., Chong, J., Clémer, K., Friess, U., Gil Ojeda, M., Goutail, F., Graves, R., Griesfeller, A., Grossmann, K., Hemerijckx, G., Hendrick, F., Herman, J., Hermans, C., Irie, H., Johnston, P. V., Kanaya, Y., Kreher, K., Leigh, R., Merlaud, A., Mount, G. H., Navarro, M., Oetjen, H., Pazmino, A., Perez-Camacho, M., Peters, E., Pinardi, G., Puentedura, O., Richter, A., Schönhardt, A., Shaiganfar, R., Spinei, E., Strong, K., Takashima, H., Vlemmix, T., Vrekoussis, M., Wagner, T., Wittrock, F., Yela, M., Yilmaz, S., Boersma, F., Hains, J., Kroon, M., Piters, A., and Kim, Y. J.: Intercomparison of slant column measurements of $\mathrm{NO}_{2}$ and $\mathrm{O}_{4}$ by MAX-DOAS and zenith-sky UV and visible spectrometers, Atmos. Meas. Tech., 3, 1629-1646, doi:10.5194/amt-3-1629-2010, 2010.

Thuillier, G., Lloyd, L., Woods, T. N., Cebula, R., Hilsenrath, E., Hersé, M., and Labs, D.,: Solar irradiance reference spectra, in: Solar variability and its effects on climate, edited by: Pap, J. M., Fox, P., Frohlich, C., Hudson, H. S., Kuhn, J., McCormack, J., North, G., and Sprigg, W., Geophysical Monograph, 141, 171194, doi:10.1029/141GM13, 2004.

Voors, R., Dobber, M., Dirksen, R., and Levelt, P.: Method of calibration to correct for cloud-induced wavelength shifts in the Aura satellite's Ozone Monitoring Instrument, Appl. Opt., 45, 36523658, doi:10.1364/ao.45.003652, 2006. 